\title{
A Study of Tourism Text Translation From the Perspective of Corpus-Based Approach*
}

\author{
QI Jian-tao \\ Ningbo Dahongying University, Ningbo, China
}

\begin{abstract}
Corpus-based translation studies is a new branch of Corpus-based linguistic studies. With the booming of Chinese tourism, tourism text translation study has come into a new stage. The application of corpus-based approach to tourism text translation study can deepen the research and help the translators in finding the essence of the translation of tourism. The paper aims at a discussion of making use of translation corpus to study the tourism text translation in the aspects of corpus construction, research tools, and research contents. With a brief analysis of corpus-based approach, the paper points out that a proper use of translation corpus in tourism text translation study may result in more scientific conclusion in interpreting some phenomena of translation and thus help better tourism text translation.
\end{abstract}

Keywords: corpus-based translation studies, tourism text translation, ways of study

\section{Introduction}

Corpus-based translation studies, as a branch of translatology, has made great progress and achievements in some traditional translation fields such as translation of literature, culture, science, and technology in recent years in China. But corpus for study of tourism text translation has not been well constructed. The study of tourism text translation is still in a traditional and low stage. The booming of domestic tourism in China makes it urgent to study tourism text translation with a more modern and scientific way by which tourism translation practice can be effectively improved. Corpus-based approach applied in tourism will lead to objective description of language in the text and text style. A contrastive analysis on English and Chinese tourism text will result in a complete and systematic description of its translation principles and methods, a mastery of its translation rules, and finally the improvement of translation quality.

\section{Literature Review}

In 1993, Mona Baker published "Corpus Linguistics and Translation Studies: Implications and Applications", which symbolizes the start of a new branch of translation studies—corpus-based translation studies. The construction of translation corpus together with its methods can uncover the essence of text translation (Baker, 1993, p. 243). Tymoczko (1999) points out that corpus-based approach will be the first choice in the future translation study. Laviosa (1998) thinks that corpus-based translation studies has constructed a

\footnotetext{
* 本文为浙江省旅游局科学研究项目阶段性成果。
}

QI Jian-tao, associate professor, College of Humanities, Ningbo Dahongying University. 
model of coherent, complete, and richer study in translation research, which concerns translation theories and practice and has set a new model. In 1995, Baker, with her colleagues, constructed the first translation corpus in the world-Translation English Corpus, with which she made a study of general characteristics of translation, the style of translators, and translation norms. The translation study thus has come into a new era and got a completely new angle of study. Baker (1995) thinks the corpus built up for translation study can be applied to the study of different aspects of translation. For instance, translation corpus can be applied to the study of linguistic characteristics of two languages and translator's translating styles. Parallel corpus can be used to study translation strategies. A scientific construction of corpus is the precondition of translation study. Zanettin (2009) thinks that what will be put into corpus should be based on the representativeness of the information. Generally, the following standards should be followed internationally: (1) books published but not newspapers, magazines, and web pages; (2) the latest corpus; and (3) the authoritative corpus. It seems a little bit unreasonable that corpus from newspapers and magazines is excluded. But it can be felt that academic research is quite cautious about the corpus selection. As for corpus tagging, Text Encoding Initiative (TEL) is widely used by researchers all over the world. As an important part of corpus construction, tagging is considered the early-stage rules of translation study (Kenny, 2001). In China, corpus translation studies mainly focuses on the following fields:

(1) The study of linguistic characteristics and general characters of translation. WANG Ke-fei (2008) reinterpreted some translation terms concerning general characters of translation and did some research on the development of the study of general characters of translation. LIAO Qi-yi (2000) studied the pros and cons of the study of general characters of translation with corpus-based approach. HU Kai-bao (2008) did some research on the Chinese sentence pattern with “把” in the Chinese translation of Hamlet by LIANG Shi-qiu and ZHU Sheng-hao respectively. WU Guang-jun (2011) made some analysis on the different collocation patterns in source language and target language on the basis of corpus.

(2) The study of translators' translating styles. The corpus-based study of the translators' translating style has been carried out by some scholars just in the recent years. LIU Ze-quan (2011) studied different translators' translating styles with an analysis of different lexical and syntactical characters and translation countermeasures in four English translations of A Dream of Red Mansions.

(3) The study of applied translation. The corpus-based study of applied translation focuses on the translation teaching. Many scholars have done some empirical research on the function of corpus in teaching translation. QIN Hong-wu (2007), LUO Xuan-min (2009), and LI De-chao (2011) have introduced the principles and methods in applying corpus to translation teaching. WANG Ke-fei (2008) and LIU Ding-jia (2011) have done further research on the ways of how to do corpus-based translation teaching, such as the combination of corpus and computer techniques, etc.

Above all, most corpus-based studies of translation concentrate on the literature field, just a little can be found in practical translation such as translation teaching. Little attention has been paid to tourism translation even tourism is flourishing all over China today. Thus, more work should be done on the corpus-based study of practical translation in order that translation quality can be improved.

\section{A Brief Introduction to Tourism Text Translation Study in China}

Many Chinese scholars have done certain research on the present situation and the main problems in tourism 
text translation since the last century, involving the types of text, style of text, functions of discourse, translation methods, and cross-cultural characteristics. They have generalized the main mistakes in tourism translation, pointing out that these mistakes are mainly concerned with spelling, grammar, Chinglish, wording, wrong expressions, missing translation, and culture misunderstanding (WEN, 2002). XU Ming-wu (2006) made a detailed analysis on the translation mistakes in the English version of an introduction to the Chinese natural cultural heritage based on the study of vocabulary, sentences, and discourse. As for translation methods, some scholars pointed out that tourism translation should emphasize its social function, namely, introduce domestic tourism resources and attract more foreign tourists. Thus, functional translation theory should be the only one to follow (JIA, 2003). Some researched on the cultural differences in tourism text between English and Chinese and translation obstacles caused by these differences. As for the differences between English tourism text and that of Chinese, researches mainly focus on the text style, discourse function, and cultural aesthetics. Chinese tourism text tends to modify and use flowery words. And in most cases historical illusions and stories of literature are included in the text. The writing of the text is more subjective. While for English tourism text, writers tend to describe just the facts and are more objective in writing (CAO, 2004). There are some common points shared by both in the discourse function in information transmission and attraction of consumers. But because of the cultural differences, English text is various form that of Chinese in standard of aesthetics. Many scholars insist on the different aesthetic psychology that leads to the differences.

To sum up, the research on the tourism text translation at home is mainly restricted in the problems of language itself and the solutions to them. The study of essence of translation is rarely found in the field of translation study. As for the translation methods, most of the study focuses on the discussion of a certain translation theory, which can hardly be applied to practice for the limitation of exemplification. But if corpus-based method can be used to study the universality, normalization, and text styles of translation of tourism text, it will make differences in the improvement of translation.

\section{Essential Methods of Corpus-Based Tourism Translation Study}

\section{Corpus Construction}

As mentioned above, corpus is the basic material of the study. Thus, it is of great importance to construct scientifically selected and fully collected corpus specifically for the study of tourism text translation. Generally, corpus of tourism mainly comes from three origins: Original English Tourism Text, Original Chinese Tourism Texts, and English Translation of Chinese Tourism Texts. With a comparatively full collection and scientific sampling of the three kinds of corpus and modern techniques, three corpuses for the study of tourism translation can be constructed, including Comparable Corpus of Original English and Chinese Tourism Texts with two sub-corpuses of English and Chinese, Comparable Corpus of English Tourism Texts with two sub-corpuses of English, and English translated from Chinese and Parallel Corpus of Chinese-English Tourism Texts with a sub-corpus of source Chinese and another of target English. In the process of constructing the corpus, much attention must be paid to the representativeness, authoritativeness, and completeness of the texts collected, and certain basic principles of text selection must be followed, without which all the later studies will be mistakenly directed. 


\section{Application of Research Tools}

At present, tools for corpus-based tourism text translation study are mainly Wordsmith Tools by Mike Scott and Paracone by Michael Barlow. Since tourism text translation study is mainly the contrastive analysis of two texts, tools mainly for quantitative study will be applied to a contrast of original English and Chinese texts, original English tests and Chinese translation as well as original Chinese texts and English translation. An analysis of the data collected will be made and rules of translation can be generalized in order that the essence of tourism text translation in its language, text style, and methods of translation can be found.

\section{Research Content}

Corpus-based tourism text translation study will focus on the following aspects. Firstly, it will perform a contrastive study of original English and Chinese tourism texts, which is based on the Comparable Corpus of English and Chinese Tourism Texts. It will first describe the linguistic characteristics of the two texts, and then have a contrast and analysis based on the data from corpus analysis. By this way the common points and differences between two texts can be found. Secondly, it will research on the discourse function of two original texts, which will also be based on the Comparable Corpus of English and Chinese Tourism Texts. Generally, the longer the discourse is, the more functions it will have. But among all the functions, one function will be most important. With this study, the discourse function of the original text will be more fully and clearly understood by translators. Thirdly, it will do a research on the contrast of English translation from Chinese texts and original English tourism texts. This study will be based on the Comparable Corpus of English Tourism Texts. With this study, the distance between English translation of Chinese tourism texts and original English tourism texts can be disclosed. The result of the study can set a base and direction for the later tourism text translation as well as uncover the problems of translation. Last but not the least, the study will also focus on the methods and principles of tourism text translation. Compared with other types of translation, tourism is more cross-linguistic, more cross-social, more cross-cultural, and more cross-psychological. Thus, corpus-based translation study can provide the translators with better ways to improve tourism text translation and make the text more communicative.

\section{Conclusion}

Corpus-based translation study makes the study of translation more objective. It starts from the basic language phenomena, and more accurately and correctly uncovers the essence of tourism text translation. Corpus-based translation study has been an important and efficient way to study and improve translation. With the booming of Chinese tourism, it becomes more and more necessary to apply this research method to tourism text translation. During the research, more emphasis should be put on the construction of corpus of tourism texts in order that some disadvantages of traditional translation can be avoided. At the same time, some modern tools should be applied in the analysis of the data from the corpus so as to make the result of the research more objective and scientific. Corpus-based tourism translation study should concentrate on the linguistic characteristics, discourse function as well as the differences between English and Chinese tourism texts. Meanwhile, it should be applied to the study of translation methods and principles of tourism texts. By this way, we are confident that tourism text translation study will be more scientific and practical, and tourism text translation will play a better and better way in cross-cultural communication. 


\section{References}

Baker, M. (1993). Corpus linguistics and translation studies: Implications and applications. In M. Baker, G. Francis, \& E. Tognini-Bonelli (Eds.), Text and technology: In honour of John Sinclair. Amsterdam \& Philadelphia: John Benjamins.

Baker, M. (1995). Corpora in translation studies: An overview and some suggestions for future research. Target, 7, 223-243.

CAO, L. J. (2004). On Sino-West culture and tourism text translation. Journal of University of Science and Technology of Suzhou, (1).

HU, K. B. (2008). A corpus-based research of Chinese translation of Hamlet. Foreign Language research, (2).

JIA, W. B. (2003). National aesthetic differences in translating tourism texts. Shanghai Journal of Translators for Science and Technology, (3).

Kenny, D. (2001). Lexis and creativity in translation. Manchester: St. Jerome Publishing.

Laviosa, S. (1998). How comparable can “comparable corpora” be. Target, 9(2), 289-319.

LI, D. C. (2011). Teaching translation of DDL based on the bilingual corpus. Computer-assisted Foreign Language Education, (11).

LIAO, Q. Y. (2000). Corpus and translation studies. Foreign Language Teaching and Research, (5).

LIU, D. J. (2011). A corpus-based reform of translation teaching. Foreign Languages and Their Teaching, (8).

LIU, Z. Q. (2011). A study of translation teaching and learners translation texts evaluation based on the corpus. Foreign Languages in China, (5).

LUO, X. M. (2009). A study of open corpus. Foreign Language Education, (6).

QIN, H. W. (2007). The application of corpus to translation teaching. Computer-Assisted Foreign Language Education, (5).

Tymoczko, M. (1999). Post-colonial writing and literary translation. London: Routledge.

WANG, K. F. (2008). Fifteen years of corpus translation studies. Foreign Languages in China, (6).

WEN, J. (2002). Coherence of information and acceptability-An investigation based on the tourism translation. Chinese Science \& Technology Translators Journal, (1).

WU, G. J. (2011). A study of collocations in translated texts based on English parallel corpus. Foreign Languages in China, (5).

XU, M. W. (2006). An analysis of translation mistakes in Chinese natural heritage text. Chinese Translators Journal, (3).

Zanettin, F. (2009). Designing an English Italian translational corpus (pp. 329-343). Beijing: World Publishing Corporation. 